\title{
PENGARUH MEDIA PENDINGIN PADA PROSES HARDENING MATERIAL BAJA S45C
}

\author{
Syaifudin Yuri, Sofyan Djamil dan M. Sobrom Yamin Lubis \\ Program Studi Teknik Mesin, Fakultas Teknik Universitas Tarumanagara, Jakarta \\ e-mail: yurisyaifudin@gmail.com
}

\begin{abstract}
Hardening is the process of heating the steel to a temperature of austenite and then dyeing is done quickly, the process is carried out to improve the properties of steel hardness. The method used in this research using books and journal literature. The purpose of this study to determine the mechanical properties of the steel that is cooled by the cooling medium brine, oil, water and air in the cooling medium to the level of violence after the S45C steel is hardened in a hardening process and microstructure. The study starts from the cutting hardness test specimen with a diameter of $65 \mathrm{~mm} \times 7$ $\mathrm{mm} \times 10 \mathrm{~mm}$ and impact test with a diameter of $10 \mathrm{~mm} \times 10 \mathrm{~mm} \times 55 \mathrm{~mm}$. The results obtained hardness test salt water has the average value of hardness $95 \mathrm{BHN}$, the average value of hardness oli $89 \mathrm{BHN}$, the average value of water hardness $94 \mathrm{BHN}$, the average value of hardness air $87 \mathrm{BHN}$ and hardness values without in hardening $88 \mathrm{BHN}$, impact test on the air has an average value $1.175 \mathrm{~J} / \mathrm{mm}^{2}$, the average value of impact brine $0.257 \mathrm{~J} / \mathrm{mm}^{2}$, the average value impact of water $0.369 \mathrm{~J} / \mathrm{mm}^{2}$, value the average impact of oil $1,128 \mathrm{~J} / \mathrm{mm}^{2}$ and average value impact without in hardening $0,955 \mathrm{~J} / \mathrm{mm}^{2}$.
\end{abstract}

Keyword: Hardening, cooling medium, mechanical properties, impact test

\begin{abstract}
Abstrak : Hardening adalah proses pemanasan baja sampai temperatur austenit dan kemudian dilakukan pencelupan cepat, proses ini dilakukan untuk meningkatkan sifat kekerasan baja. Metode yang digunakan dalam penelitian ini yaitu menggunakan buku literatur dan jurnal. Tujuan dari penelitian ini untuk mengetahui sifat mekanik baja yang didinginkan dengan media pendingin air garam, oli, air dan udara dalam media pendingin terhadap tingkat kekerasan pada baja S45C setelah dikeraskan dalam proses hardening dan struktur mikro. Penelitian dimulai dari pemotongan specimen uji kekerasan dengan diameter $65 \mathrm{~mm} \times 7 \mathrm{~mm} \times 10 \mathrm{~mm}$ dan uji impact dengan diameter $10 \mathrm{~mm}$ × $10 \mathrm{~mm}$ × $55 \mathrm{~mm}$. Hasil yang diperoleh uji kekerasan air garam memiliki nilai rata-rata kekerasan 95 BHN, nilai rata-rata kekerasan oli 89 BHN, nilai rata-rata kekerasan air 94 BHN, nilai rata-rata kekerasan udara 87 BHN dan nilai kekerasan tanpa di hardening $88 \mathrm{BHN}$. uji impact pada udara memiliki nilai rata-rata $1,175 \mathrm{~J} / \mathrm{mm}^{2}$, nilai rata-rata impact air garam $0,257 \mathrm{~J} / \mathrm{mm}^{2}$, nilai rata-rata impact air $0,369 \mathrm{~J} / \mathrm{mm}^{2}$, nilai rata-rata impact oli $1,128 \mathrm{~J} / \mathrm{mm}^{2}$ dan nilai rata-rata impact tanpa dihardening 0,955 $\mathrm{J} / \mathrm{mm}^{2}$.
\end{abstract}

Kata Kunci : Hardening, media pendingin, sifat mekanik, uji impact

\section{PENDAHULUAN}

Baja karbon merupakan paduan dari baja dan karbon dan sudah digunakan sejak dunia industri mulai berdiri, Penggunaan material dibidang industri semakin meningkat sehingga dibutuhkan material yang mempunyai sifat-sifat mekanik yang baik. Tiap material yang digunakan di industri, memerlukan sifat yang berbeda-beda sehingga perlu dilakukan proses lanjutan seperti perlakuan panas untuk mendapatkan sifat yang sesuai dengan kebutuhan.

Terdapat berbagai media quenching yang dapat digunakan untuk proses hardening, seperti air garam, air, oli dan udara. Untuk itu perlu dilakukan kajian pengaruh media pendingin terhadap sifat mekanik dan struktur mikro baja S45C pada proses hardening.

\section{METODE PENELITIAN}

Metode penelitian dibuat untuk menyusun langkah-langkah yang akan dilakukan dalam melakukan penelitian sehingga penelitian berjalan secara sistematis dan terarah. Adapun langkahlangkah yang dilakukan dapat dilihat dalam Gambar 1 di bawah ini. Setelah pengujian dilakukan, data-data yang didapat akan dianalisa lebih lanjut. Tahap terakhir adalah kesimpulan dan saran. 


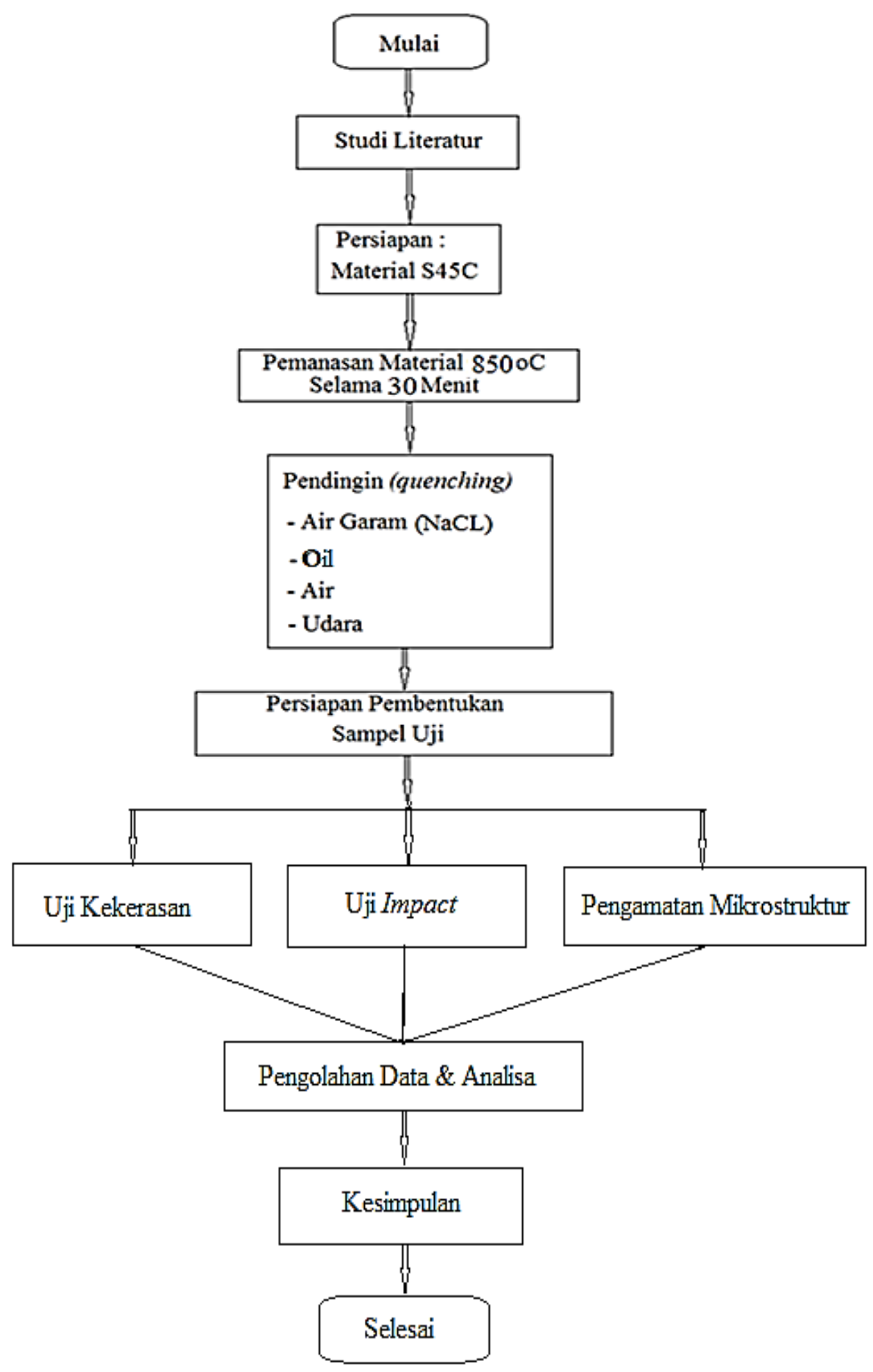

Gambar 1. Diagram alir metode penelitian

Spesimen yang dipakai dalam setiap pengujian memiliki dimensi yang berbeda, yaitu sebagai berikut:

\section{A. Spesimen uji kekerasan}

Pemotongan sampel uji kekerasan yaitu 65 mm x 7 mm x 10 mm 


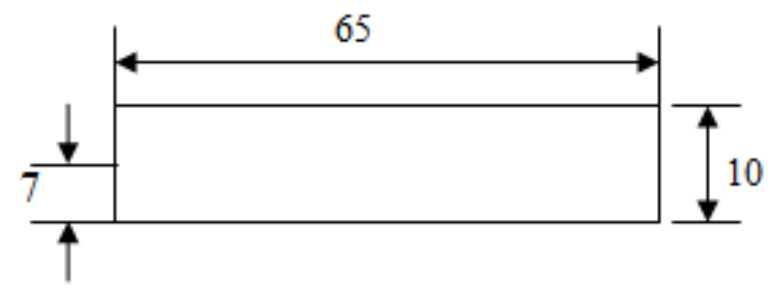

Gambar 2. Dimensi Spesimen Uji Kekerasan

\section{B. Spesimen uji impact}

Pemotongan sampel uji impact yaitu $10 \mathrm{~mm}$ x $10 \mathrm{~mm}$ x $55 \mathrm{~mm}$

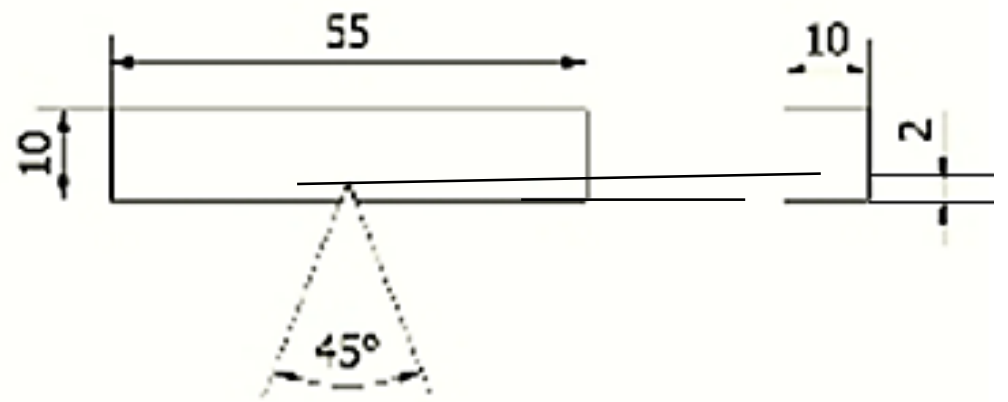

Gambar 3. Dimensi Spesimen Uji Impact

\section{Pengamatan Metalografi}

Pemotongan spesimen cukup dalam dimensi yang tdak terlalu besar ( $<10 \mathrm{~mm}$ x $10 \mathrm{~mm}$ x 10 $\mathrm{mm}$ ) dan tidak boleh terjadi panas berlebihan dalam proses pemotongan untuk menghindari rusaknya struktur spesimen tersebut akibat panas.

\section{HASIL DAN PEMBAHASAN}

\section{A. Hasil Data Uji Kekerasan Brinell}

Tabel 1. Nilai rata-rata dari hasil uji kekerasan tanpa dihardening

\begin{tabular}{|l|c|c|c|c|c|c|}
\hline \multirow{2}{*}{ Spesimen } & \multicolumn{5}{|c|}{ Nilai Kekerasan (BHN) } & Kekerasan Rata-rata \\
\cline { 2 - 6 } & A & B & C & D & E & \\
\hline Spesimen 1 & 88 & 85 & 89 & 90 & 91 & 88 \\
\hline Spesimen 2 & 87 & 90 & 82 & 91 & 85 & 87 \\
\hline Spesimen 3 & 84 & 87 & 88 & 90 & 90 & 87 \\
\hline \multicolumn{7}{|c|}{ Rata - rata } \\
\hline
\end{tabular}

Tabel 2. Nilai rata-rata dari hasil uji kekerasan setelah dihardening dengan media pendingin oli

\begin{tabular}{|c|c|c|c|c|c|c|}
\hline \multirow{2}{*}{ Spesimen } & \multicolumn{7}{|c|}{ Nilai Kekerasan (BHN) } & $\begin{array}{c}\text { Kekerasan Rata-rata } \\
\text { (BHN) }\end{array}$ \\
\cline { 2 - 6 } & A & B & C & D & E & 88 \\
\hline Spesimen 1 & 91 & 86 & 91 & 91 & 85 & 89 \\
\hline Spesimen 2 & 89 & 89 & 91 & 90 & 90 & 89 \\
\hline Spesimen 3 & 91 & 87 & 89 & 90 & 88 & 89 \\
\hline \multicolumn{7}{|c|}{ Rata - rata } \\
\hline
\end{tabular}


Tabel 3. Nilai rata-rata dari hasil uji kekerasan setelah dihardening dengan media pendingin air garam

\begin{tabular}{|l|c|c|c|c|c|c|}
\hline \multirow{2}{*}{ Spesimen } & \multicolumn{5}{|c|}{ Nilai Kekerasan (BHN) } & $\begin{array}{c}\text { Kekerasan Rata-rata } \\
\text { (BHN) }\end{array}$ \\
\cline { 2 - 6 } & A & B & C & D & E & \\
\hline Spesimen 1 & 95 & 90 & 95 & 86 & 95 & 92 \\
\hline Spesimen 2 & 96 & 94 & 96 & 94 & 96 & 96 \\
\hline Spesimen 3 & 96 & 93 & 97 & 96 & 95 & 95 \\
\hline \multicolumn{7}{|c|}{ Rata - rata } \\
\hline
\end{tabular}

Tabel 4. Nilai rata-rata dari hasil uji kekerasan setelah dihardening dengan media pendingin air

\begin{tabular}{|c|c|c|c|c|c|c|}
\hline \multirow{2}{*}{ Spesimen } & \multicolumn{5}{|c|}{ Nilai Kekerasan (BHN) } & \multirow{2}{*}{$\begin{array}{c}\text { Kekerasan Rata-rata } \\
\text { (BHN) }\end{array}$} \\
\cline { 2 - 6 } & A & B & C & D & E & 92 \\
\hline Spesimen 1 & 85 & 94 & 93 & 93 & 96 & 93 \\
\hline Spesimen 2 & 96 & 85 & 97 & 96 & 92 & 96 \\
\hline Spesimen 3 & 95 & 96 & 95 & 97 & 97 & 94 \\
\hline \multicolumn{7}{|c|}{ Rata - rata } \\
\hline
\end{tabular}

Tabel 5. Nilai rata-rata dari hasil uji kekerasan setelah dihardening dengan media pendingin udara

\begin{tabular}{|c|c|c|c|c|c|c|}
\hline \multirow{2}{*}{ Spesimen } & \multicolumn{5}{|c|}{ Nilai Kekerasan (BHN) } & $\begin{array}{c}\text { Kekerasan Rata-rata } \\
\text { (BHN) }\end{array}$ \\
\cline { 2 - 6 } & A & B & C & D & E & 88 \\
\hline Spesimen 1 & 84 & 92 & 85 & 89 & 90 & 87 \\
\hline Spesimen 2 & 88 & 85 & 88 & 90 & 88 & 84 \\
\hline Spesimen 3 & 84 & 79 & 87 & 85 & 87 & 87 \\
\hline \multicolumn{7}{|c|}{ Rata - rata }
\end{tabular}

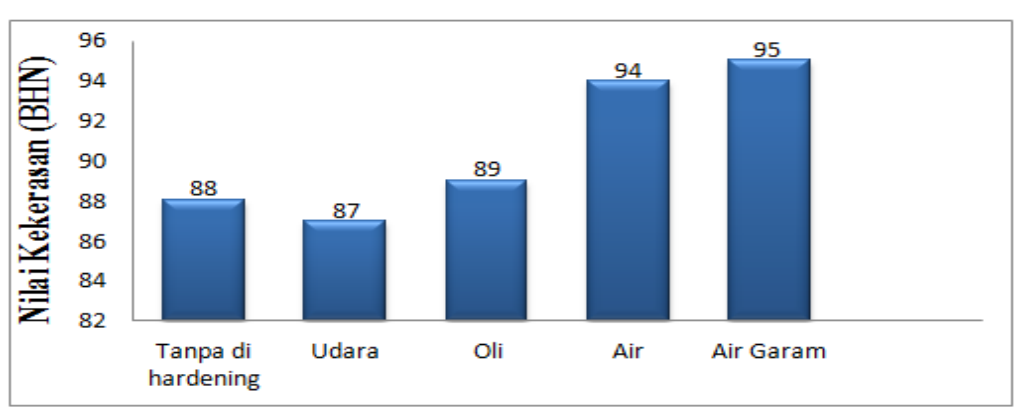

Gambar 4. Grafik perbandingan hasil uji kekerasan sebelum dan sesudah dilakukan proses hardening

Dari hasil persentase material baja yang di hardening dengan media pendingin udara mengalami penurunan, sedangkan persentase material baja yang di hardening dengan media pendingin oli, air, dan air garam mengalami peningkatan. Hasil uji kekerasan dengan metode Brinell diperoleh hasil sebagai berikut : hardening dengan media pendingin udara didapat hasil 87 BHN, tanpa di hardening 88 BHN, hardening dengan media pendingin oli yaitu 89 BHN, 
hardening dengan media pendingin air yaitu 94 BHN, dan hardening dengan media pendingin air garam diperoleh hasil 95 BHN. Hasil tersebut dapat dilihat bahwa kekerasan yang paling rendah yaitu hardening dengan media pendingin udara dan kekerasan tertinggi dengan media pendingin air garam didapat hasil 95 BHN. Udara memiliki kekerasan rendah, karena udara tidak memiliki viskositas tetapi hanya memiliki massa jenis sehingga laju pendinginannya lambat dibanding dengan air garam yang memiliki viskositas yang rendah sehingga nilai kekentalan cairan kurang, sehingga laju pendinginannya cepat dan massa jenisnya besar.

\section{B. Hasil Data Penelitian Uji Impact Charpy}

Tabel 6. Hasil perhitungan uji impact charphy tanpa dihardening

\begin{tabular}{|c|c|c|c|c|c|}
\hline Spesimen & Usaha (W) & $\begin{array}{c}1 \\
(\mathrm{~mm})\end{array}$ & $\begin{array}{c}\mathrm{h} \\
(\mathrm{mm})\end{array}$ & $\begin{array}{c}\text { Luas penampang } \\
\left(A_{0}\right) \\
\left(\mathrm{mm}^{2}\right)\end{array}$ & $\begin{array}{c}\text { Nilai impact } \\
(\mathrm{K})\end{array}$ \\
\hline Spesimen 1 & $80,458 \mathrm{~J}$ & 10 & 8 & 80 & $1,005 \mathrm{~J} / \mathrm{mm}^{2}$ \\
\hline Spesimen 2 & $86,608 \mathrm{~J}$ & 10 & 8 & 80 & $1,082 \mathrm{~J} / \mathrm{mm}^{2}$ \\
\hline Spesimen 3 & $62,265 \mathrm{~J}$ & 10 & 8 & 80 & $0,778 \mathrm{~J}^{2} \mathrm{~mm}^{2}$ \\
\hline \multicolumn{7}{|c|}{ Rata-rata } & $0,955 \mathrm{~J}^{2} \mathrm{~mm}^{2}$ \\
\hline
\end{tabular}

Tabel 7. Hasil perhitungan uji impact charphy setelah dihardening dengan media pendingin oli

\begin{tabular}{|c|c|c|c|c|c|}
\hline Spesimen & Usaha (W) & $\begin{array}{c}1 \\
(\mathrm{~mm})\end{array}$ & $\begin{array}{c}\mathrm{h} \\
(\mathrm{mm})\end{array}$ & $\begin{array}{c}\text { Luas penampang } \\
\left(A_{0}\right) \\
\left(\mathrm{mm}^{2}\right)\end{array}$ & $\begin{array}{c}\text { Nilai impact } \\
(\mathrm{K})\end{array}$ \\
\hline Spesimen 1 & $89,683 \mathrm{~J}$ & 10 & 8 & 80 & $1,121 \mathrm{~J} / \mathrm{mm}^{2}$ \\
\hline Spesimen 2 & $138,624 \mathrm{~J}$ & 10 & 8 & 80 & $1,732 \mathrm{~J} / \mathrm{mm}^{2}$ \\
\hline Spesimen 3 & $42,535 \mathrm{~J}$ & 10 & 8 & 80 & $0,531 \mathrm{~J} / \mathrm{mm}^{2}$ \\
\hline \multicolumn{7}{|c|}{ Rata-rata } & $1,128 \mathrm{~J} / \mathrm{mm}^{2}$ \\
\hline
\end{tabular}

Tabel 8. Hasil perhitungan uji impact charphy setelah dihardening dengan media pendingin air garam

\begin{tabular}{|c|c|c|c|c|c|}
\hline Spesimen & Usaha (W) & $\begin{array}{c}1 \\
(\mathrm{~mm})\end{array}$ & $\begin{array}{c}\mathrm{h} \\
(\mathrm{mm})\end{array}$ & $\begin{array}{c}\text { Luas penampang } \\
\left(A_{0}\right) \\
\left(\mathrm{mm}^{2}\right)\end{array}$ & $\begin{array}{c}\text { Nilai impact } \\
(\mathrm{K})\end{array}$ \\
\hline Spesimen 1 & $17,167 \mathrm{~J}$ & 10 & 8 & 80 & $0,214 \mathrm{~J} / \mathrm{mm}^{2}$ \\
\hline Spesimen 2 & $12,555 \mathrm{~J}$ & 10 & 8 & 80 & $0,156 \mathrm{~J} / \mathrm{mm}^{2}$ \\
\hline Spesimen 3 & $32,029 \mathrm{~J}$ & 10 & 8 & 80 & $0,400 \mathrm{~J} / \mathrm{mm}^{2}$ \\
\hline \multicolumn{7}{|c|}{ Rata-rata } & $0,257 \mathrm{~J} / \mathrm{mm}^{2}$ \\
\hline
\end{tabular}

Tabel 9. Hasil perhitungan uji impact charphy setelah dihardening dengan media pendingin air

\begin{tabular}{|c|c|c|c|c|c|}
\hline Spesimen & Usaha (W) & $\begin{array}{c}1 \\
(\mathrm{~mm})\end{array}$ & $\begin{array}{c}\mathrm{h} \\
(\mathrm{mm})\end{array}$ & $\begin{array}{c}\text { Luas penampang } \\
\left(A_{0}\right) \\
\left(\mathrm{mm}^{2}\right)\end{array}$ & $\begin{array}{c}\text { Nilai impact } \\
(\mathrm{K})\end{array}$ \\
\hline Spesimen 1 & $34,592 \mathrm{~J}$ & 10 & 8 & 80 & $0,432 \mathrm{~J} / \mathrm{mm}^{2}$ \\
\hline Spesimen 2 & $32,029 \mathrm{~J}$ & 10 & 8 & 80 & $0,400 \mathrm{~J} / \mathrm{mm}^{2}$ \\
\hline Spesimen 3 & $22,036 \mathrm{~J}$ & 10 & 8 & 80 & $0,275 \mathrm{~J}^{2} \mathrm{~mm}^{2}$ \\
\hline \multicolumn{7}{|c|}{ Rata-rata } & $0,369 \mathrm{~J}^{2} \mathrm{~mm}^{2}$ \\
\hline
\end{tabular}


Tabel 10. Hasil perhitungan uji impact charphy setelah dihardening dengan media pendingin udara

\begin{tabular}{|c|c|c|c|c|c|}
\hline Spesimen & Usaha (W) & $\begin{array}{c}1 \\
(\mathrm{~mm})\end{array}$ & $\begin{array}{c}\mathrm{h} \\
(\mathrm{mm})\end{array}$ & $\begin{array}{c}\text { Luas } \\
\text { penampang } \\
\left(A_{0}\right) \\
\left(\mathrm{mm}^{2}\right)\end{array}$ & Nilai impact (K) \\
\hline Spesimen 1 & $102,494 \mathrm{~J}$ & 10 & 8 & 80 & $1,281 \mathrm{~J} / \mathrm{mm}^{2}$ \\
\hline Spesimen 2 & $89,683 \mathrm{~J}$ & 10 & 8 & 80 & $1,121 \mathrm{~J} / \mathrm{mm}^{2}$ \\
\hline Spesimen 3 & $89,683 \mathrm{~J}$ & 10 & 8 & 80 & $1,121 \mathrm{~J} / \mathrm{mm}^{2}$ \\
\hline \multicolumn{6}{|c|}{ Rata-rata } \\
\hline
\end{tabular}

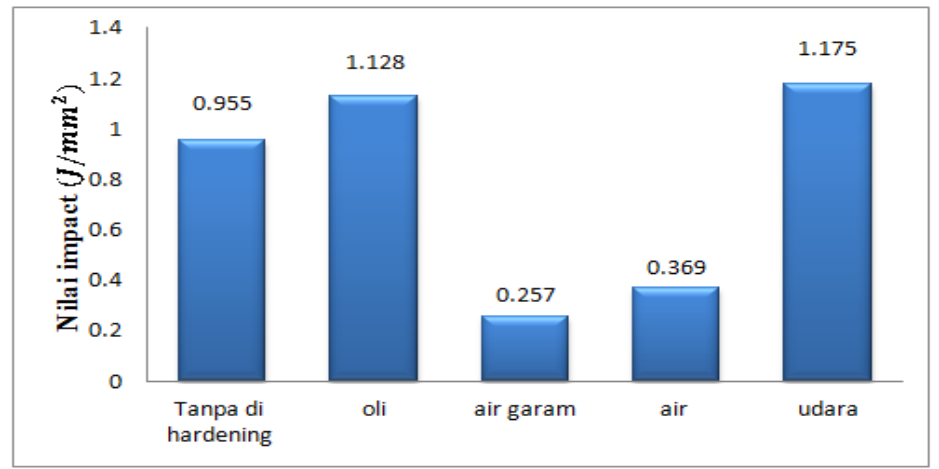

Gambar 5. Grafik Perbandingan Rata-rata Nilai Impact Tanpa Hardening dan Sesudah Hardening

Material baja yang telah di hardening dengan media pendingin oli dan udara memiliki nilai impact yang lebih kecil dari material yang tidak di hardening, ini menandakan material baja yang di hardening dengan media pendingin oli dan udara kegetasanya menurun, sedangkan yang di hardening dengan media pendingin air garam nilai impact-nya lebih besar dibanding dengan material yang tidak di hardening ini menandakan material yang di hardening dengan media pendingin air garam bertambah getas (brittle). Semakin getas suatu material keuletannya akan semakin rendah, sehingga spesimen lebih mudah dipatahkan dengan energi yang relatif lebih rendah. Udara paling rendah pada pengujian kekerasan (Brinell) pada uji impact mendapatkan kuletan yang paling tinggi. Karena sifat material dari udara memiliki ketahanan terhadap ulet yang lebih baik dari ketahanan terhadap beban.

\section{Pengamatan struktur mikro}

Struktur awal benda kerja seperti terlihat pada gambar 6 terdiri dari struktur Ferrit yang berwarna putih dan perlit yang berwarna hitam, hal tersebut disebabkan karena komposisi benda kerja yang mengandung 0,44 \% karbon dan termasuk baja hypotectoid

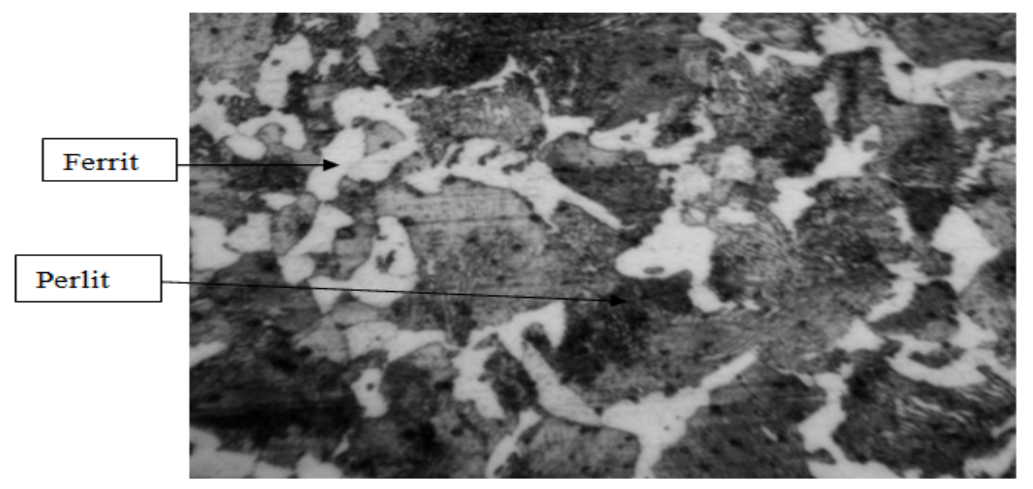

Gambar 6. Struktur mikro baja S45C sebelum dilakukan pemanasan di etsa dengan nital 3\% ; perbesaran $500 \mathrm{X}$. 
Struktur mikro dapat dilihat pada Gambar 7 Struktur terbentuk ketika karbon terperangkap jadi tingkat kekerasannya kecil dan fasa martensit lebih sedikit dibandingkan dengan air. karakteristik quenching di oli relatif homogen, jadi oli lebih rendah dari air karena efisiensi pendinginan dari oli beberapa kali lebih rendah dari air karena panas spesifik, panas laten penguapan dan konduktivitas termal dari oli lebih rendah daripada air.

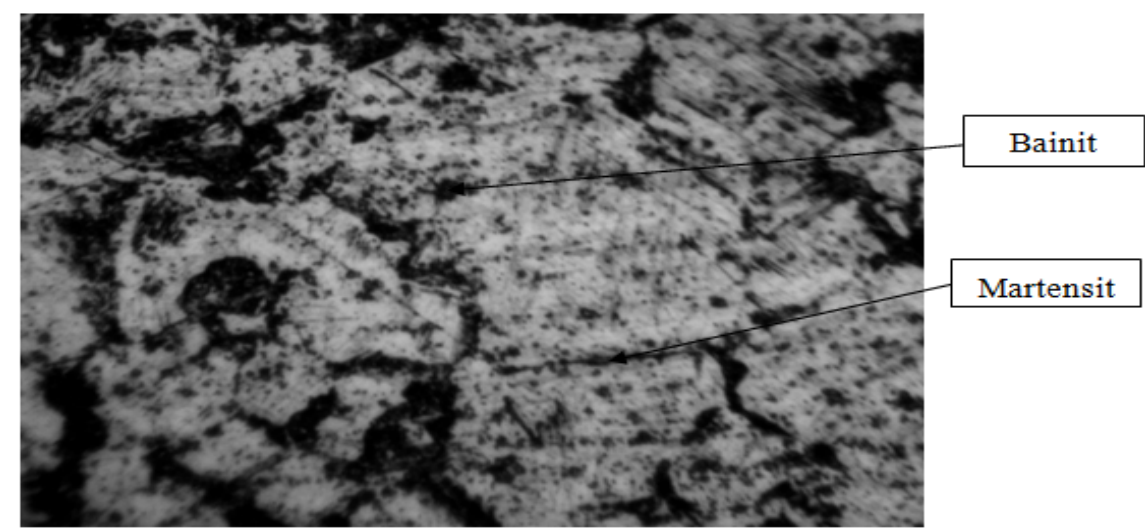

Gambar 7. Struktur mikro baja S45C setelah dilakukan pemanasan $850{ }^{\circ} \mathrm{C}$ dengan waktu tahan 30 menit di quenching dalam oli; etsa nital 3\% ; perbesaran $500 \mathrm{X}$.

Struktur mikro benda dapat dilihat pada Gambar 8 Media pendingin air garam, yang terbentuk adalah martensite. Transformasi bainit mencakup perubahan struktur diikuti dengan distribusi ulang karbon yang berpresipitasi sebagai karbida. Fasa austenite di quenching kedalam air garam, untuk mencegah difusi atom karbon, sisa karbon terperangkap dalam struktur kisi, menimbulkan regangan kisi setempat yang menghambat pergerakan dislokasi. Struktur ini terbentuk ketika karbon terperangkap dalam kisi kristal. Air garam memiliki laju pendinginan yang paling cepat maka fasa martensit yang terbentuk lebih banyak dibandingkan dengan menggunakan media air, udara dan oli.

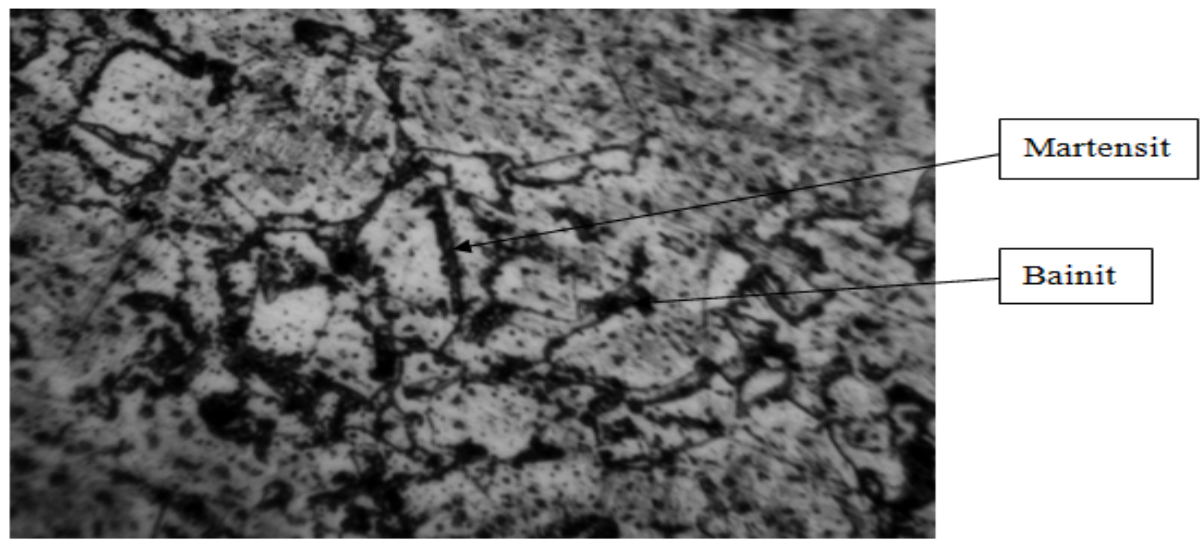

Gambar 8. Struktur mikro baja S45C setelah dilakukan pemanasan $850{ }^{\circ} \mathrm{C}$ dengan waktu tahan 30 menit di quenching dalam air garam; etsa nital 3\% ;perbesaran 500X.

Struktur mikro dapat dilihat Gambar 9 Media pendingin air, fasa yang terbentuk adalah martensite. Terbentuknya fasa bainit karena merupakan campuran fasa perlit dan sementit. Pada waktu pendinginan yang cepat pada fasa austenit tidak sempat berubah menjadi ferit atau perlit karena tidak ada kesempatan bagi atom-atom karbon yang telah larut dalam austenit untuk mengadakan pergerakan difusi dan bentuk sementit oleh karena itu terjadi fase mertensit. Air 
memiliki massa jenis yang besar tapi lebih kecil dari air garam, kekentalannya rendah sama dengan air garam dan laju pendinginannya lebih lambat dari air garam.

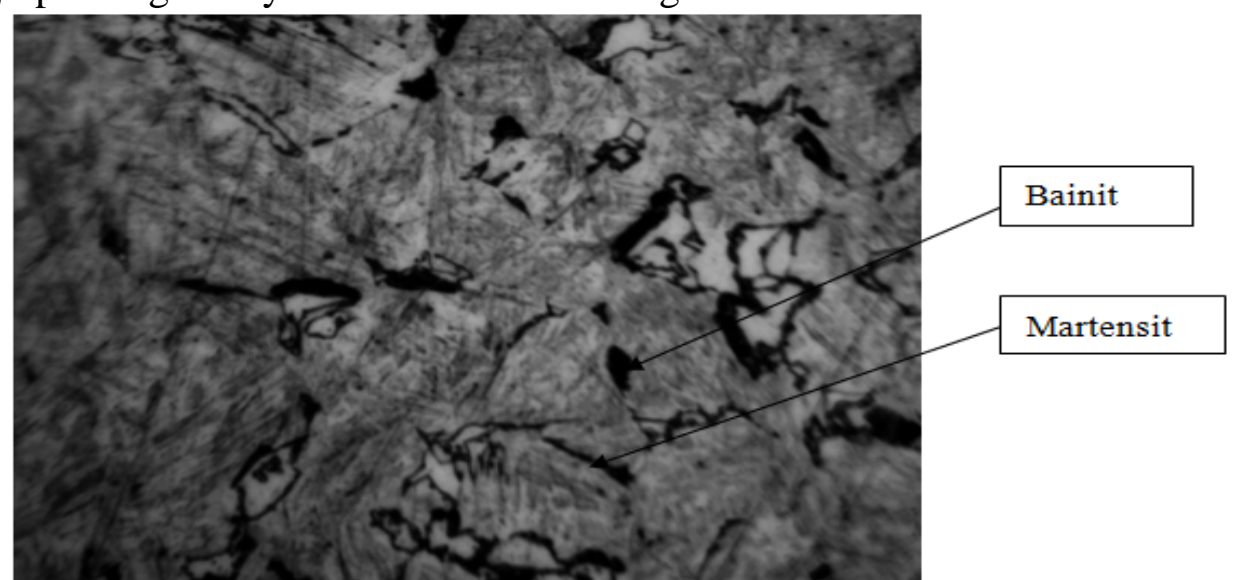

Gambar 9. Struktur mikro baja S45C setelah dilakukan pemanasan $850^{\circ} \mathrm{C}$ dengan waktu tahan 30 menit di quenching dalam air; etsa nital 3\%; perbesaran $500 \mathrm{X}$.

Struktur mikro benda kerja setelah dilakukan proses diatas seperti terlihat pada gambar 10 . Penurunan suhu yang terjadi sangat lambat maka fasa yang terbentuk adalah austenit dan perlit. Pertumbuhan perlit meliputi pertumbuhan ferrit dan sementit sekaligus secara bersamaan. Pertumbuhan dimulai dengan terjadinya sementit pada batas butir austenite. Sementit tumbuh dengan didahului oleh difusi atom-atom karbon, sehingga akhirnya berubah menjadi perlit.

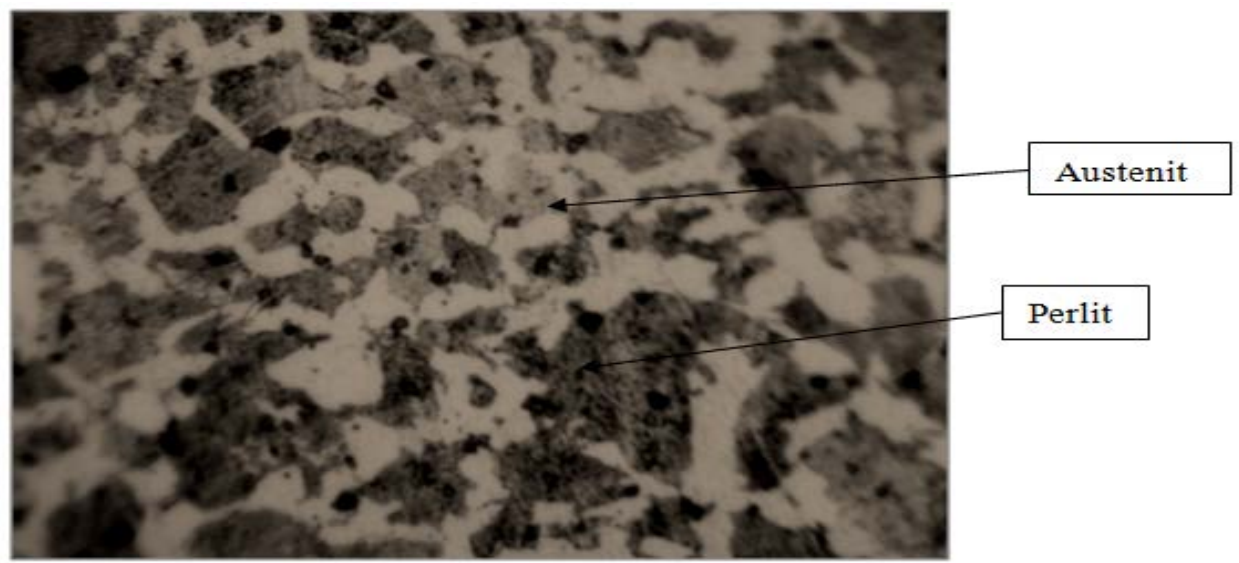

Gambar 10. Struktur mikro baja S45C setelah dilakukan pemanasan $850{ }^{\circ} \mathrm{C}$ dengan waktu tahan 30 menit di quenching dalam udara; etsa nital 3 \%; perbesaran $500 \mathrm{X}$.

\section{KESIMPULAN}

Berdasarkan penelitian yang telah dilakukan dapat ditarik kesimpulan, yaitu Hasil yang diperoleh uji kekerasan air garam memiliki nilai rata-rata kekerasan 95 BHN, nilai rata-rata kekerasan oli 89 BHN, nilai rata-rata kekerasan air 94 BHN, nilai rata-rata kekerasan udara 87 BHN dan nilai kekerasan tanpa di hardening 88 BHN. uji impact pada udara memiliki nilai ratarata $1,175 \mathrm{~J} / \mathrm{mm}^{2}$, nilai rata-rata impact air garam $0,257 \mathrm{~J} / \mathrm{mm}^{2}$, nilai rata-rata impact air 0,369 $\mathrm{J} / \mathrm{mm}^{2}$, nilai rata-rata impact oli $1,128 \mathrm{~J} / \mathrm{mm}^{2}$ dan nilai rata-rata impact tanpa dihardening 0,955 $\mathrm{J} / \mathrm{mm}^{2}$.

\section{DAFTAR PUSTAKA}

[1]. William, F. Smith. Structure and Properties of Engineering Alloys, Me Graw - Hill Book Company, New York, 1981.

[2]. Tata Surdia, Shinroku Saito. Pengetahuan Bahan Teknik, PT Pradnya Paramita Jakarta, 1985. 
[3]. Suratman, Rochim. Panduan Proses Perlakuan Panas. Lembaga Penelitian ITB. Bandung, 1994.

[4]. Harry, Chandler. Hardness Testing, 2nd Edition, ASM Internasional, 1999.

[5]. Fajar, Ismail. Rancang Bangun Uji Impak Charpy, Tugas Akhir. Semarang : Fakultas Teknik, Universitas Diponegoro, 2012.

[6]. Thelning, K Erick. Steel and it's Heat Treatment, Second Edition, Butterworths, 1994.

[7]. Grode, Antonsson, Springer Handbook of Mechanical Engineering, Volume 10. 1822.

[8]. Kennard Dhammabhakti, Uji Impact, Laporan Praktikum Metalurgi Fisik. Jakarta : Fakultas Teknik, Universitas Tarumanagara. 2014. 